\title{
Sharing Progress in Neonatology (SPIN): Moving towards Individualized Prenatal and Neonatal Care
}

Incorporating the 33rd International Workshop on Surfactant Replacement, Lübeck, May 31 - June 2, 2018

From May 31 to June 2, 2018, the third Sharing Progress in Neonatology (SPIN) meeting incorporating the 33rd International Workshop on Surfactant Replacement took place in Lübeck, the former capital of the Hanseatic League. The "Hanse" unified the common interests of merchants over a couple of centuries in medieval times. In those days trade connections were spread out all over Europe, and so Lübeck, a city that became a UNESCO World Cultural Heritage center more than 30 years ago, was an inspiring venue for this meeting. The first SPIN meeting in Naples in 2016 focused on neonatal lung and brain research [1], whilst at the second meeting in Dublin in 2017 the topics included neonatal brain, gut, heart, and lung research [2]. This year in Lübeck the main theme was the development of individualized prenatal and neonatal care.

The meeting was opened by Colin J. Morley from Cambridge giving the 10th Bengt Robertson Memorial Lecture. Bengt Robertson, the founder of the International Workshop on Surfactant Replacement and a pioneer in surfactant research [3, 4], died in 2008 and will always be remembered as the driving force behind this workshop. The aim of this meeting has always been to promote science, but also to allow lively debates on basic research and how to translate new findings into clinical practice. The title of the 10th Bengt Robertson Memorial Lecture: "Monitoring neonatal resuscitation: why is it needed?" is an excellent example of how progress was made in neonatology in the last few decades [5]. Misbeliefs and wrong interpretations of the pathophysiology of perinatal adaptation led neonatologists to the inappropriate use of, for example, oxygen, suctioning, and intubation. Professor Morley clarified the mistakes that were made on the way and illustrated how neonatologists moved (slowly) to a more evidence-based approach [6]. He strongly advocated monitoring of physiological variables and simultaneous video recording during resuscitation procedures as a means of improving outcomes [5].

The second invited speaker was Stuart Hooper from Melbourne, VIC, Australia. Using modern imaging technologies like the synchrotron, he and his collaborators focused on the mechanisms of postnatal adaption. "Air has to enter the lung and blood has to flow" summarizes the task at the very beginning of life. How can functional residual capacity be established? How do ventilation and systemic and pulmonary circulation interact? What is the role of the circulating blood volume and 
benefit of late cord clamping? What else can we do to support nature? These were just some of the topics that were addressed during his excellent lecture [7].

Umberto Simeoni from Lausanne, Switzerland, described the effects of pre- and perinatal programming in his lecture on the "Perinatal origins of adult disease" [8]. Diabetes, hypertension, obesity, and the metabolic syndrome in adult life are just some of the disorders that have their origins in pregnancy and early life. Early prevention, optimal prenatal nutrition, and specific followup measures are key factors in early preservation of longterm health [8]. Professor Simeoni shared recent findings on these topics, but also pointed out how much further research is needed in this important area [9].

David Edwards from London is an expert on perinatal brain injury. In his lecture entitled "New aspects in the diagnosis and treatment of perinatal brain injury" he addressed many topics. Is early magnetic resonance imaging (MRI) really helpful for clinical management of affected neonates? Brain cooling is widely accepted, but do we really know how to do it properly? Are there additional drugs in the pipeline that may lead to better longterm outcome? These were just some of the issues addressed during Professor Edwards' lecture [10].

Professor Jan Deprest from Leuven, Belgium, is one of the leading experts in prenatal therapy. In his lecture on "Prenatal modulation of lung hypoplasia: where are we?" he focused on the current knowledge of the state of the art of the tracheal occlusion technique in infants with lung hypoplasia due to congenital diaphragmatic hernia. He clearly pointed out that there is no "one size fits all" solution. The degree of lung hypoplasia has to be determined (for example by lung to head ratio/using ultrasound or fetal MRI) and the parents have to be informed and counseled about the risk and outcome of this procedure [11]. New studies will address the question of whether prenatal treatment of pregnant mothers with drugs like sildenafil may become an option in the future.

Wolfgang Göpel from Lübeck, Germany, gave a lecture on "The genetic background of neonatal disease" [12]. Using one of the largest cohorts worldwide that sampled genetic material from very low birth weight infants, he demonstrated the possibilities, but also the limitations, of genetic analyses [13]. Of more than 27,000 human genes that have been sequenced only a few are relevant for common human diseases. Professor Göpel's lecture described the genetics of common traits and diseases with a particular focus on drug discovery and drug therapy in neonates [12]. With the costs of genetic anal-

SPIN: Moving towards Individualized Prenatal and Neonatal Care yses dropping all the time, will whole genome sequencing become standard in NICUs in the near future?

The last of the lectures that are summarized in this issue of Neonatology was given by Vassilios A. Fanos from Cagliari, Italy, entitled "Clinical metabolomics in neonatology: from metabolites to diseases" [14]. This is an issue of current debate. In this "omics" science field, metabolites in biological samples like blood, saliva, or breast milk have been measured and correlated with neonatal disorders [15]. Professor Fanos presented metabolomics data on relevant neonatal disorders and discussed the 5 most important metabolites [14]. Although these preliminary data will need further studies it is hoped that this knowledge will allow an approach of "personalized neonatology" in the future, enabling individualized treatments based on specific metabolic features. Can we expect better outcomes even stretching into adult life from these novel technologies?

The SPIN debates were introduced as a new format during this meeting. In the first debate Angela Kribs from Cologne, Germany, an expert on minimal handling approaches in neonatology, was opposed by Charles Roehr from Oxford, UK, on the subject of minimal handling versus invasive and noninvasive ventilation in very preterm infants. Charles Roehr pointed out how little evidence there is that noninvasive ventilation is really better than other forms of respiratory support. For example, a recent publication from Australia did not find advantages in terms of long-term outcome when analyzing lung function of children at school age who were treated in different time periods when either mechanical ventilation or continuous positive airway pressure was used in the majority of infants [16].

The second debate focused on the role of probiotics in neonatology. Kate Costeloe from London, UK, pointed out how contradictory the clinical studies were and how important it is to look at the individual composition of the probiotic preparations used in different studies. The pro-speaker, Christoph Härtel from Lübeck, Germany, emphasized the importance of the microbiome and the therapeutic options that could arise from increasing knowledge in this field.

The SPIN updates comprised talks on topics that are very relevant in daily practice on the NICU: "Neonatal jaundice - a puzzle still unresolved" (speaker: Thor Willy Ruud Hansen, Oslo, Norway), "Apnoea, intermittent hypoxia and bradycardia" - should we bother? (speaker: Christian Poets, Tübingen, Germany), "Breast is best also for preemies" (speaker: Hans van Goudoever, Rotterdam, The Netherlands), "What is the right tempera- 
ture for a neonate?” (speaker: Dominique Singer, Hamburg, Germany), and "Pulmonary hypertension in the neonate - any progress?" (speaker: Manuel Sanchez Luna, Madrid, Spain).

The meeting also included 12 short oral presentations published as abstracts in this issue together with the selected lectures. Fourteen poster presentations underlined the interactive and international nature of SPIN 2018. At the conclusion of SPIN 2018 the more than 300 attendees from over 50 countries had information/approaches/guidelines to take home for improvement of their clinical care of the newborn.

Ten years after his death and more than 30 years after the introduction of surfactant into neonatal medicine, Bengt Robertson would have been delighted to see how surfactant research really catalyzed progress in neonatal medicine far beyond pulmonary problems. As often, del- egates left the meeting with some answers but a lot of open questions, so that all look forward to SPIN 2019 in Parma, Italy.

Egbert Herting, Lübeck
Tore Curstedt, Stockholm
Henry L. Halliday, Belfast
Mikko Hallman, Oulu
Ola D. Saugstad, Oslo
Christian P. Speer, Würzburg

\section{Disclosure Statement}

The scientific program was arranged by the Scientific Committee without interference from the sponsors. All members of the Scientific Committee are or have been consultants to Chiesi Farmaceutici. The content of the meeting and workshop reflects the scientific opinions of the individual presenters and not the view of the sponsor.

\section{References}

1 Buonocore G, Curstedt T, Halliday HL, Hallman M, Saugstad OD, Speer CP: Sharing progress in neonatal (SPIN) lung and brain. Neonatology 2016;109:322-324.

2 Molloy EJ, Curstedt T, Halliday HL, Hallman M, Saugstad OD, Speer CP: Sharing progress in neonatal (SPIN) brain, gut, heart, and lung. Neonatology 2017;111:384-387.

3 Curstedt T, Halliday HL, Speer CP: A unique story in neonatal research: the development of a porcine surfactant. Neonatology 2015; 107:321-329.

4 Halliday HL, Speer CP: Bengt Robertson (1935-2008): a pioneer and leader in surfactant research. Neonatology 2009;95:VI-VIII.

5 Morley C: Monitoring neonatal resuscitation: why is it needed? Neonatology 2018; 113:387-392.

6 Schmölzer GM, Te Pas AB, Davis PG, Morley CJ: Reducing lung injury during neonatal resuscitation of preterm infants. J Pediatr 2008; 153:741-745.
7 Hooper SB, Kitchen MJ, Polglase GR, Roehr CC, Te Pas AB: The physiology of neonatal resuscitation. Curr Opin Pediatr 2018;30:187191.

8 Simeoni U, Armengaud JB, Siddeek B, Tolsa JF: Perinatal origins of adult disease. Neonatology 2018;113: 393-399.

9 Simeoni U, Bocquet A, Briend A, Chouraqui JP, Darmaun D, Dupont C, Feillet F, Frelut ML, Girardet JP, Goulet O, Hankard R, Rieu D, Rozé JC, Turck D, Vidailhet M; Comité de nutrition de la Société française de pédiatrie: Early origins of adult disease (in French). Arch Pediatr 2016;23:443-446.

10 Counsell SJ, Ball G, Edwards AD: New imaging approaches to evaluate newborn brain injury and their role in predicting developmental disorders. Curr Opin Neurol 2014;27:168175.
11 Russo FM, De Coppi P, Allegaert K, Toelen J, van der Veeken L, Attilakos G, Eastwood MP, David AL, Deprest J: Current and future antenatal management of isolated congenital diaphragmatic hernia. Semin Fetal Neonatal Med 2017;22:383-390.

12 Göpel W, Westermann E, Pagel F: The genetic background of neonatal disease. Neonatology 2018;113:400-405.

13 Göpel W, Drese J, Rausch TK, Twisselmann N, Bohnhorst B, Müller A, Franz A, Ziegler A, Härtel C, Herting E: Necrotizing enterocolitis and high intestinal iron uptake due to genetic variants. Pediatr Res 2018;83:57-62.

14 Fanos V, Pintus R, Dessì A: Clinical metabolomics in neonatology: from metabolites to diseases. Neonatology 2018;113:406-413.

15 Noto A, Fanos V, Dessì A: Metabolomics in newborns. Adv Clin Chem 2016;74:35-61.

16 Doyle LW, Ranganathan S, Cheong JL: Ventilation in preterm infants and lung function at 8 years. N Engl J Med 2017;377:1601-1602. 